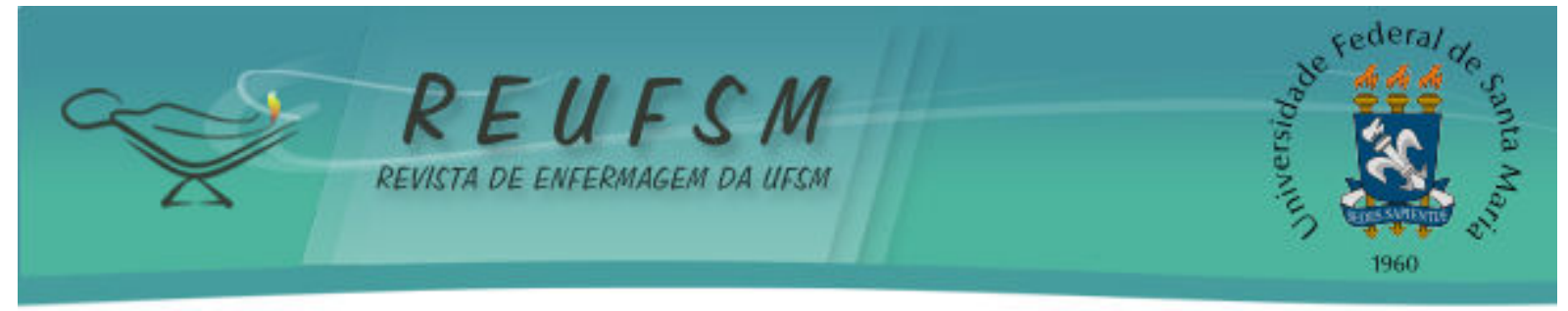

ARTIGO ORIGINAL

\title{
IMPORTÂNCIA DO VÍNCULO ENTRE PROFISSIONAL-USUÁRIO NA ESTRATÉGIA DE SAÚDE DA FAMÍLIA
}

\author{
IMPORTANCE OF THE BOND BETWEEN PROFESIONAL AND USER IN FAMILY HEALTH \\ STRATEGY
}

\section{IMPORTANCIA DEL VINCULO ENTRE PROFESIONAL-USUARIO EN LA ESTRATEGIA SALUD DE LA FAMILIA}

Raionara Cristina de Araújo Santos ${ }^{1}$

Francisco Arnoldo Nunes de Miranda²

Doi: $10.5902 / 2179769217313$

RESUMO: Objetivo: descrever a importância do vínculo entre profissional e usuários na Saúde da Família, a partir da ótica do enfermeiro, médico e odontólogo, preceptores do Programa de Educação pelo Trabalho e para a Saúde. Método: estudo descritivoexploratório, de abordagem qualitativa. Realizado com 15 profissionais da Estratégia de Saúde da Família de Natal, Rio Grande do Norte, Brasil, em 2010. Utilizou-se entrevista individual semiestruturada. Os dados foram categorizados com o ALCESTE e analisados com auxílio da análise de conteúdo. Resultados: obtiveram-se duas categorias: vínculo como principal ferramenta de consolidação da Estratégia Saúde da Família; vínculo como recurso terapêutico. O vínculo perpassa por uma relação tipo sujeito-sujeito, construído na tessitura das redes de informações existentes no território. Considerações finais: 0 vínculo constituiu-se em elemento imprescindível para o fortalecimento das relações no âmbito da saúde da família. Corresponde a uma ferramenta para o cuidado, assim como recurso terapêutico para o acompanhamento dos indivíduos e famílias.

Descritores: Saúde da família; Relações profissional-família; Prática profissional; Estratégia saúde da família; Preceptoria.

ABSTRACT: Aim: to describe the importance of the bond between professional and users in the Family Health, from the perspective of a nurse, a doctor and a dentist, who are preceptors of the Education Program for Work and Health. Methods: descriptive exploratory study, with a qualitative approach. It was performed with 15 professionals of the Family Health Strategy of Natal, Rio Grande do Norte, Brazil, in 2010. We used semistructured individual interviews. Data were categorized by ALCESTE and analyzed using content analysis. Results: there were two categories: bond as the main tool of consolidation of the Family Health Strategy; bond as therapeutic resource. The bond permeates a relationship of the type subject-subject, built on existing information networks tessitura in the territory. Conclusion: The bond showed to be an essential element to strengthen relations in the Family Health. It is a tool for care, as well as a therapeutic resource for the monitoring of individuals and families.

Descriptors: Family Health; Professional-family relations; Professional practice; Family Health Strategy; Preceptorship.

RESUMEN: Objetivo: describir la importancia del vínculo profesional-usuarios en salud de la familia, desde la perspectiva de una enfermera, médico y dentista, preceptores del Programa de Educación para el Trabajo y la Salud. Método: estudio exploratorio

\footnotetext{
1 Enfermeira. Pós-Doutora em Enfermagem pela Universidade Federal do Rio Grande do Norte. Natal, Rio Grande do Norte, Brasil. E-mail: raionara_cristina@yahoo.com.br

2 Enfermeiro. Professor Doutor do Departamento de Enfermagem da Universidade Federal do Rio Grande do Norte. Natal, Rio Grande do Norte, Brasil. E-mail: farnoldo@gmail.com
} 


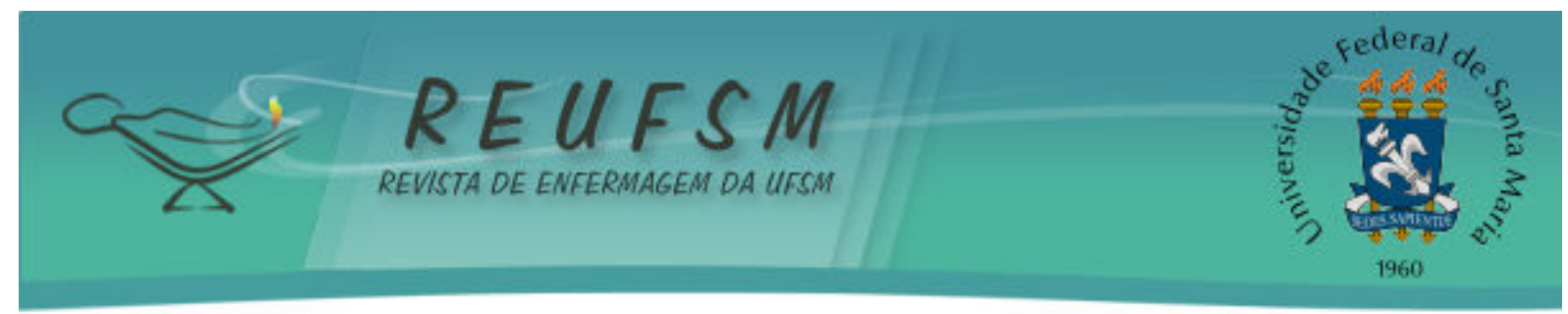

descriptivo, enfoque cualitativo. Realizado con 15 profesionales de Estrategia de Salud de la Familia de Natal, Rio Grande do Norte, Brasil, en 2010. Se utilizó entrevistas semiestructuradas individuales. Los datos se clasificaron por ALCESTE y fueron analizados mediante análisis de contenido. Resultados: se obtuvieron dos categorías: vínculo como la principal herramienta de consolidación del ESF; vínculo como un recurso terapéutico. El vínculo impregna un tipo de relación sujeto-objeto, construido en el tejido de las redes de información existentes en el territorio. Conclusión: El vínculo es un elemento esencial en el fortalecimiento de las relaciones dentro de la Salud de la Familia. Corresponde a un dispositivo de atención, así como recurso terapéutico para el seguimiento de personas y familias.

Descriptores: Salud de la família; Relaciones profesional-familia; Práctica profesional; Estrategia de Salud Familiar; Preceptoria.

\section{INTRODUÇÃO}

As políticas de saúde no Brasil trilharam por diversos caminhos no intuito de superar a exclusão de milhões de indivíduos do sistema de saúde culminando, em 1986, na $8^{a}$ Conferência Nacional de Saúde. Essa conferência constituiu o marco fundamental para a construção das bases doutrinárias da criação do Sistema Único de Saúde (SUS). Em 1994, com a finalidade de implementar os princípios e diretrizes do SUS, adotou-se a estruturação do Programa Saúde da Família (PSF), decorrente do Programa de Agentes Comunitários de Saúde (PACS). Em 1998, considerando-se a expansão e potencialidades do PSF, este programa passou a ser denominado de Estratégia de Saúde da Família (ESF), por sua capacidade em orientar a organização dos sistemas municipais de saúde sendo, portanto, mais complexo que um simples programa. ${ }^{1}$

A Estratégia de Saúde da Família (ESF) se define como um modelo de atenção primária à saúde que inclui diferentes elementos, operacionalizado por meio de ações/estratégias de promoção e proteção da saúde, prevenção de doenças, diagnóstico, tratamento, recuperação e reabilitação, tanto do indivíduo como sua família e comunidade. ${ }^{2}$ Para isso, a ESF se baseia em princípios norteadores objetivando o desenvolvimento de práticas de saúde articuladas às Redes de Atenção à Saúde. Dessa forma, utiliza tecnologias de elevada complexidade e baixa densidade, bem como serviços assistenciais (ambulatoriais, hospitalares e de apoio diagnóstico) e de vigilância em saúde (ambiental, epidemiológica e sanitária), valorizando o território e os diversos contextos em que os usuários estão inseridos. ${ }^{3}$

A atuação territorializada promove o vínculo com a população por meio do fortalecimento das ações intersetoriais com o estímulo à participação da comunidade. A família se torna o objeto primeiro da atenção, compreendida a partir do ambiente onde vive e de sua interação com o mesmo, bem como das suas relações com os serviços de saúde em que está inserida, considerando-se o conjunto de determinantes sociais, políticos e econômicos que os permeiam - família, profissionais e serviços de saúde. ${ }^{4}$

0 estudo demonstrou a relevância do vínculo entre o profissional de saúde e o usuário nas possibilidades de sucesso e fracasso de um determinado tratamento ${ }^{5}$ consistindo em uma estratégia de promoção da integralidade e singularidade do cuidado em saúde. ${ }^{6} 0$ vínculo também consiste em uma ferramenta para a compreensão ampliada do processo saúde-doença e necessidade de intervenções identificadas a partir de demandas e problemas, ${ }^{7}$ interferindo na satisfação do usuário em relação a ESF. ${ }^{8}$

Nesse aspecto, o vínculo se revela como um elemento ao mesmo tempo facilitador e desafiador na ESF, tornando-se necessária a ampliação das discussões para a resolução da lacuna no conhecimento acerca da importância do mesmo para o desenvolvimento e 


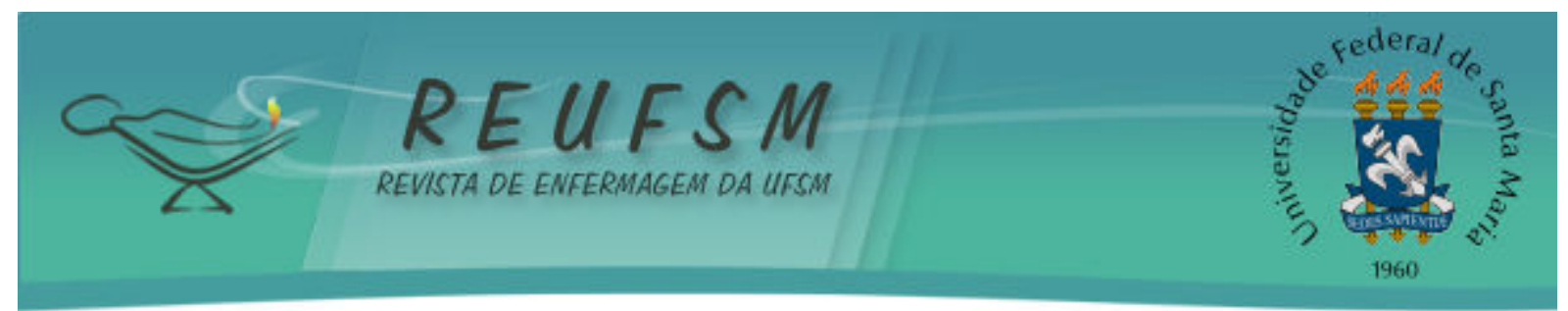

reorganização das práticas profissionais visando à centralização do cuidado no usuário, a partir da ótica dos próprios profissionais.

A partir do exposto, elaborou-se o seguinte questionamento: na perspectiva dos preceptores do Programa de Educação pelo Trabalho e para a Saúde (PET-Saúde), qual a importância do vínculo entre profissionais e usuários no âmbito da Saúde da Família para o fortalecimento da ESF? Portanto, o presente estudo objetivou descrever a importância do vínculo entre profissional e usuários na Saúde da Família, a partir da ótica do enfermeiro, médico e odontólogo, preceptores do Programa de Educação pelo Trabalho e para a Saúde (PET-Saúde).

Destaca-se que os profissionais de saúde vinculados ao PET-Saúde influenciam, direta ou indiretamente, o processo ensino-aprendizagem e de trabalho dos futuros profissionais não somente do ponto de vista técnico-metodológico, mas também do ponto de vista social e intersubjetivo.

\section{MÉTODO}

Trata-se de um estudo descritivo e exploratório, com abordagem qualitativa. Realizado em sete unidades de Estratégia de Saúde da Família que integram o Programa de Educação pelo Trabalho e para a Saúde (PET-Saúde) ${ }^{9}$ do município de Natal, Rio Grande do Norte, Brasil.

Regulamentado em março de 2010, pela Portaria Interministerial MS/MEC $n^{\circ} 421,{ }^{10}$ - PET-Saúde consiste numa parceria entre o Ministério da Saúde e o Ministério da Educação. O objetivo é de fomentar Grupos de Aprendizagem Tutorial (GTs) na ESF para desenvolver ações indissociáveis de ensino-pesquisa-extensão, na perspectiva da integração dos cursos de graduação com o serviço e a comunidade, e da formação acadêmica socialmente comprometida e cidadã. ${ }^{9}$

A pesquisa foi realizada com quinze preceptores do PET-Saúde da Família em Natal (RN), sendo cinco de categoria (Enfermagem, Medicina e Odontologia), obtidos por meio dos critérios de inclusão e exclusão dos participantes. Definiram-se como critérios de inclusão: ser um dos profissionais de nível superior (Enfermagem, Medicina e Odontologia); comprovar vínculo efetivo a partir de seis meses com a unidade de saúde em que trabalha; confirmar cadastrado no projeto PET-Saúde da Família de Natal como preceptor. Excluíram-se os profissionais que estavam afastados do serviço, de licença médica ou maternidade e aqueles que se encontravam de férias durante o período de coleta dos dados.

Respeitaram-se os aspectos éticos da pesquisa envolvendo seres humanos, com sua aprovação pelo Comitê de Ética em Pesquisa da Universidade Federal do Rio Grande do Norte (CEP-UFRN), parecer $n^{\circ}$ 019/2010, CAAE: 0211.0.051.000-09. Além disso, todos os participantes foram informados do objetivo da pesquisa e assinaram o Termo de Consentimento Livre e Esclarecido - TCLE, em duas vias, conforme a Resolução n¹96/1996, vigente na época do estudo. ${ }^{11}$

Os dados foram coletados no período de abril a junho de 2010, nos locais de trabalho dos participantes, com o uso de entrevista individual semiestruturada, as quais foram audiogravadas. Esclarece-se que todos os participantes foram denominados com pseudônimos referentes a nomes de pintores brasileiros.

0 instrumento de pesquisa era composto por duas partes: a primeira correspondeu à identificação sócio-demográfica dos profissionais, enquanto a segunda apresentava cinco perguntas abertas: 0 que representa, para você, a Estratégia de Saúde da Família (ESF)? Quais os pontos fortes e as fragilidades que você observa na ESF? Quais as suas competências na ESF? Que soluções você adotaria para melhorar o processo de produção 


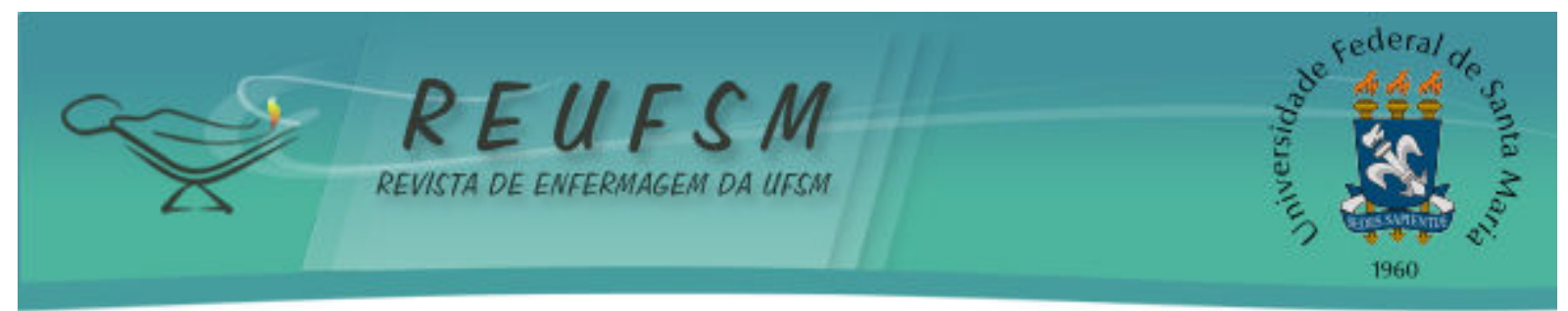

dos serviços de saúde na ESF? Quais as contribuições e/ou interferências ocorridas após a sua inserção no Projeto PET-Saúde da Família Natal (RN)?

Os dados referentes à identificação dos participantes foram digitados e tabulados no software Microsoft Excel versão 2007. As entrevistas, com duração aproximada de 30 a 40 minutos, foram transcritas e digitadas em documento do Microsoft Word versão 2007, categorizadas com o auxílio do software Analyse Lexicale par Contexte d'un Ensemble de Segments de Texte (ALCESTE) e, posteriormente, submetidas à análise de conteúdo de Bardin. ${ }^{12}$

O ALCESTE trabalha com um único arquivo, em formato texto (extensão txt), denominado de corpus, que é preparado seguindo critérios previamente estabelecidos pelo programa a partir de um conjunto de textos. Na sua análise, o programa reúne as raízes semânticas por meio de classes, considerando a função de cada vocábulo dentro de um determinado texto. ${ }^{13}$

As falas dos participantes, transcritas e digitadas no Microsoft Word, geraram um corpus o qual foi submetido ao software ALCESTE para realizar a separação e categorização das mesmas. Após essa etapa, utilizou-se a análise de conteúdo de Bardin, ${ }^{12}$ utilizando-se os seguintes passos: (1) leitura flutuante do material obtido com o software ALCESTE; (2) exploração das falas; (3) elaboração de inferências e nomeação das categorias, considerando-se as semelhanças e as diferenças entre as falas.

Após esse processo, identificaram-se duas categorias: Vínculo como principal ferramenta de consolidação da Estratégia de Saúde da Família; Vínculo como recurso terapêutico.

\section{RESULTADOS E DISCUSSÃO}

De modo geral, o perfil dos enfermeiros, médicos e odontólogos preceptores do PET-Saúde da Família de Natal (RN), caracterizou-se como do sexo feminino (73,3\%), com idade variando de 46 a 52 anos $(46,6 \%)$, casados $(73,3 \%)$ e renda mínima de seis salários $(80 \%)$.

Neste estudo, o vínculo se estabeleceu a partir da compreensão de uma relação tipo sujeito-sujeito, do espaço de atuação profissional com a inclusão do contexto local, modos e estilos de vida e a ampliação do eu com o outro para o sujeito-sujeito-família e comunidade, construído na tessitura das redes de informações existentes no território.

0 conceito de vínculo é polissêmico. Perpassa áreas diversas das ciências sociais e da saúde com caráter e abordagens variadas tais como: dimensão, estratégia, diretriz, objetivo, tecnologia e relação. ${ }^{14}$

\section{Vínculo como principal ferramenta de consolidação da ESF}

0 vínculo como um conceito emergente e articulado dos processos de trabalho do enfermeiro, médico e odontólogo foi evidenciado como um dos pontos mais fortes da ESF.

Acho que o ponto forte principal é a questão do vínculo. É a gente tá no domicílio. Então, você conhece o paciente, sua família, aonde mora. Você consegue saber o que se passa, porque as coisas não estão andando, como é que você pode intervir na situação de saúde. [...] E os alunos do PET já conseguem identificar isso no nosso dia-a-dia (Yara Tupinambá, Enfermeira) 


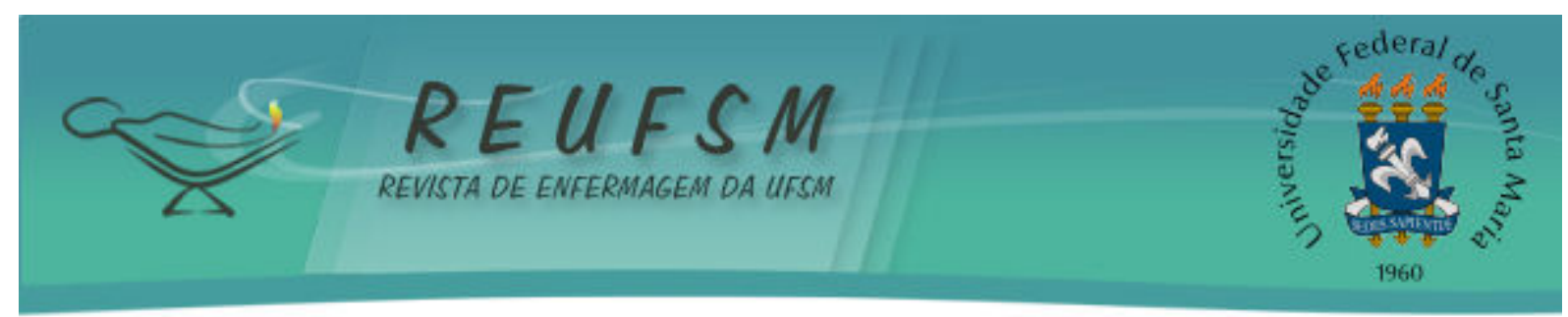

O ponto forte que eu acho primordial é esse vínculo, essa visão do todo, do indivíduo-família-comunidade. $E$ a gente não consegue ver isso isolado, não consegue atuar isoladamente, nem que a gente queira, porque ele é tão forte, é tão concreto, que não consegue. (Beatriz Milhazes, Enfermeira)

[...] o vínculo é coisa forte, eu acho que beneficia muito a população. Tem uma resposta maior, o compromisso é maior. (Zina Aita, Médica)

A gente atende o paciente e ele não vai desaparecer. Você pode visitá-lo, você tem aquele acompanhamento do paciente, da família. Às vezes, ele chega na cadeira e a gente sabe "por que você está assim hoje?' Porque a gente vai criando um vínculo, eu acho isso muito importante. E é isso que passo para os alunos do PET. (Djanira da Motta e Silva, Odontóloga)

Dessa forma, o vínculo constitui-se num elo forte entre profissional e usuário, garantindo segurança no que concerne ao atendimento de suas necessidades. 0 indivíduo, pertencente àquela área de cobertura da ESF, acredita e confia que ao chegar à unidade de saúde ou no seu próprio domicílio receberá atenção de algum dos profissionais responsáveis por sua área. Apesar de parecer algo simples, a formação desse vínculo requer, de ambos, profissional e usuário, momentos de conversação, escuta, acolhimento, trocas, responsabilização em torno do problema que será enfrentado e, consequentemente, vínculo. ${ }^{5}$

O estabelecimento do vínculo com as famílias consiste numa das diretrizes da ESF. No campo da saúde pública, o vínculo representa uma conexão entre os conceitos de humanização, responsabilização, acolhimento e integralidade. 0 estabelecimento das bases dessa relação vincular prescinde da confiança, do respeito, da atenção, da escuta e de um olhar diferenciado dos profissionais para com os usuários e vice-versa. ${ }^{6,15-16}$

Tal fato propicia uma relação compromissada entre a equipe, o usuário e a família, direcionando os profissionais para uma atuação humanizada, voltada para escuta, conhecimento das necessidades e prioridades dos usuários e construção de intervenções terapêuticas individuais. Promove uma compreensão ampliada do processo saúde-doença e dos pontos de vulnerabilidade. ${ }^{6,7}$

Esse vínculo assumido pelos profissionais do estudo como um conceito articulado entre ESF e PET-Saúde da Família, constitui-se na principal ferramenta que o profissional utiliza para obter o conhecimento acerca das subjetividades, individualidades e condições de vida das famílias.

A Estratégia de Saúde da Família é uma relação de vínculo com o indivíduo, família e comunidade, porque é uma interação sujeitosujeito quando o cliente vem à unidade, quando fala de uma situação e a gente sabe toda situação familiar dele, onde se encontra, como é o aspecto emocional. (Beatriz Milhazes, Enfermeira)

O conhecimento que você tem da família, de onde aquele paciente está inserido, em que contexto. [...] O PET-Saúde é importante 


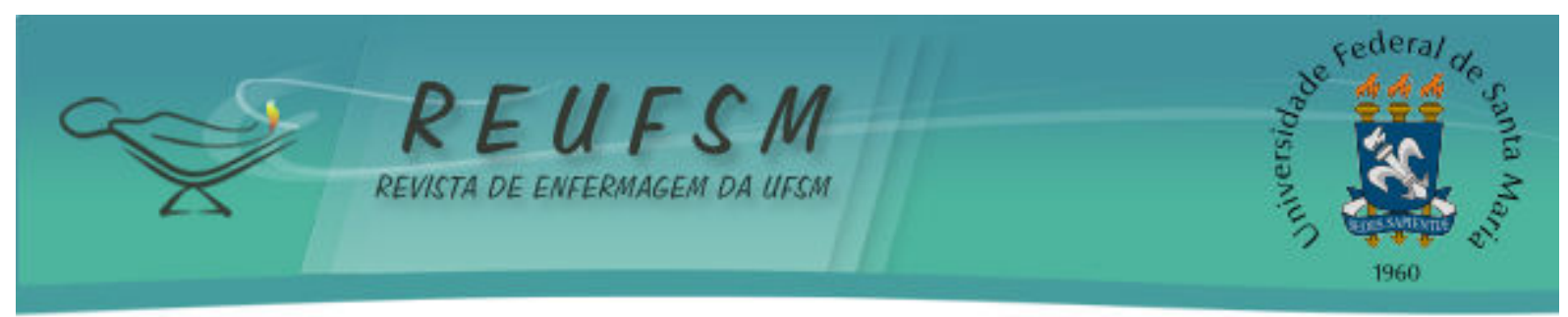

porque consegue mostrar isso para os alunos (Tarcila do Amaral, Médica)

As minhas competências principais são estabelecer vínculos e a partir desses vínculos melhorar a condição de saúde e a vida do paciente e das famílias, das quais sou responsável. (Zina Aita, Médica)

Acho que a Estratégia de Saúde da Família veio pra gente ver a pessoa e a família como um todo, porque eu trabalhei em unidade básica comum, onde saia seis, dez fichas e a gente não tinha elo com as pessoas, a gente não conhecia o eu do paciente e hoje é muito bom, a gente tem vínculo. (Djanira da Motta e Silva, Odontóloga)

De acordo com as falas dos participantes, observa-se que o vínculo ultrapassa uma simples relação profissional para algo mais complexo e próximo da realidade do usuário. Os profissionais conseguem identificar além dos problemas de saúde, ou seja, o contexto em que o indivíduo e a família estão inseridos, a condição de saúde, o aspecto emocional do usuário.

A formação do vínculo entre profissional e usuário promove uma relação de confiança e respeito que acontece por meio da identificação das necessidades do usuário. Consiste numa ferramenta imprescindível para uma boa adesão do usuário ao seu tratamento farmacológico, como também às propostas da Estratégia Saúde da Família. ${ }^{17}$ Com isso, pode-se inferir que quanto mais apropriado for o vínculo, melhor será o resultado, pois maior será a troca de saberes entre os trabalhadores da saúde e os usuários. $^{18}$

Um estudo ${ }^{16}$ realizado com famílias de uma ESF no Estado de Minas Gerais mostrou que a formação do vínculo profissional-usuário necessita que os profissionais se insiram na comunidade, despindo-se de (pré)conceitos e discursos verticalizados, a fim de conhecer a realidade de cada indivíduo e família. Diante disso, salienta-se a importância que o território possui no desenvolvimento das práticas profissionais na ESF, permitindo aos trabalhadores de saúde o acompanhamento das famílias residentes naquela determinada área.

As características positivas da ESF estão relacionadas, essencialmente, à expansão dos cuidados primários no Brasil por meio da adscrição de clientela e do reconhecimento do território e das condições socioeconômicas e epidemiológicas, possibilitando estabelecer vínculos entre os usuários e suas famílias com os profissionais de uma determinada equipe. ${ }^{3,17}$

A territorialização é uma forma de atuar numa delimitação espacial previamente determinada, denominada de território. Constitui-se em uma metodologia capaz de promover transformações no modelo assistencial e nas práticas sanitárias vigentes, a partir da compreensão da lógica das relações entre ambiente, condições de vida, situação de saúde, produção de subjetividades e acesso às ações e serviços de saúde. ${ }^{19,20}$

Todos os aspectos mostrados anteriormente acerca do vínculo como ferramenta para a consolidação da ESF são particularmente importantes porque são relatos de profissionais responsáveis pela preceptoria e formação dos estudantes da área da saúde. Busca-se ampliar as discussões acerca das competências a serem desenvolvidas na formação de um novo perfil profissional de acordo com as diretrizes educacionais e políticas de saúde. Objetiva-se que os discentes percebam, desde muito cedo, a 


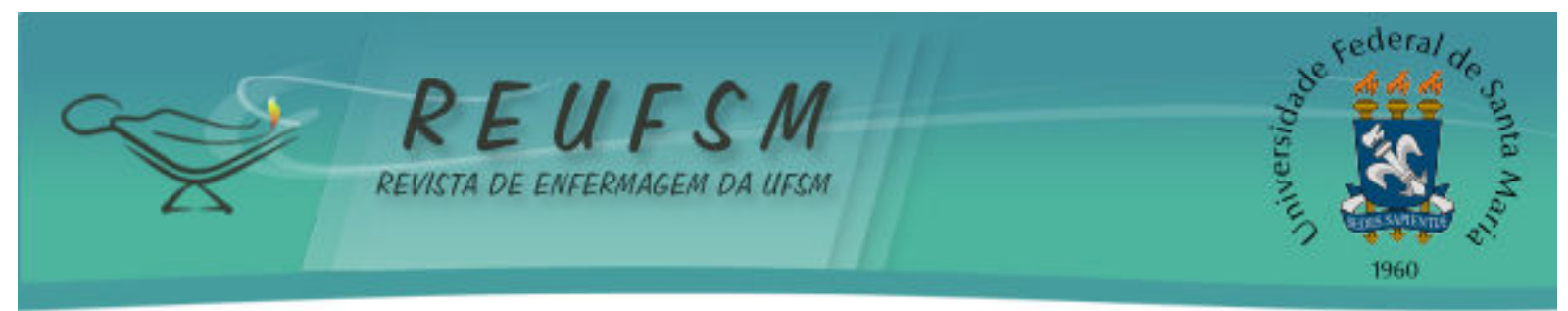

necessidade do acolhimento, da escuta, da humanização e, consequentemente, do vínculo nas teias de relações existentes no âmbito da saúde da família.

\section{Vínculo como recurso terapêutico}

O vínculo tem sido utilizado como uma maneira de organizar o relacionamento entre equipes de saúde e sua população usuária. Faz-se indispensável, para isso, o estabelecimento de laços interpessoais fortes que reflitam a cooperação mútua entre profissionais e usuários e, consequentemente, um cuidado compartilhado e humanizado.

[...] praticar uma atividade especializada, mas que seja mais focada pra quebra de preconceitos do ponto de vista de hierarquia, que o médico esteja sempre mais próximo do paciente. (Zina Aita Médica)

Existe um vínculo, é uma estratégia que faz com que você se supere, esteja sempre renovando sua energia, tentando fazer com que suas estratégias atinjam o objetivo como, por exemplo, cuidando de uma gestante no pré-natal, então, há a ideia de que ela chegue no final da gestação, que o nenê nasça bem. (Marysia Portinari, Enfermeira)

Acho que é [o vínculo] um desafio para as equipes. Acho que é a gente perceber, ao longo desses onze anos que estou aqui,e agora no PET-Saúde, resultados como a diminuição do óbito infantil, a questão do melhoramento do aleitamento materno e outras coisas. (Georgina Albuquerque, Enfermeira).

De acordo com as falas dos participantes, percebe-se que a construção do vínculo gera no profissional de saúde um sentimento de renovação e reenergização na sua prática profissional. Além disso, o vínculo revela-se como um recurso terapêutico que ocasiona o encontro e seguimento de um determinado usuário e/ou família, permitindo ao binômio profissional-usuário atingir os objetivos e metas traçados.

0 vínculo também permite a desconstrução da hierarquia do profissional sobre o usuário ao permitir uma maior aproximação entre ambos por meio de períodos de conversação, escuta e troca de conhecimentos. Qualquer abordagem assistencial entre profissional de saúde e usuário se produz por meio de um trabalho vivo, em que coexistem diversos processos relacionais advindos do encontro entre duas pessoas que atuam uma sobre a outra, gerando momentos de escuta, trocas, conflitos, responsabilização, compromisso, confiança e, consequentemente, vínculo. ${ }^{21}$

Neste contexto, pode-se considerar o vínculo como uma "tecnologia leve" do cuidado, pois permite que os profissionais conheçam os usuários e as prioridades e singularidades de cada um, ${ }^{6,16}$ facilitando-lhes a compreensão dos problemas, o seguimento e a melhor forma de intervenção e tratamento desses usuários.

Entretanto, salienta-se a necessidade da formação de um vínculo responsável e positivo, caso contrário, haverá um padrão paternalista, no qual o emocional pode interferir na relação profissional-usuário, gerando uma relação negativa de dependência, descaracterizando sua competência terapêutica. 


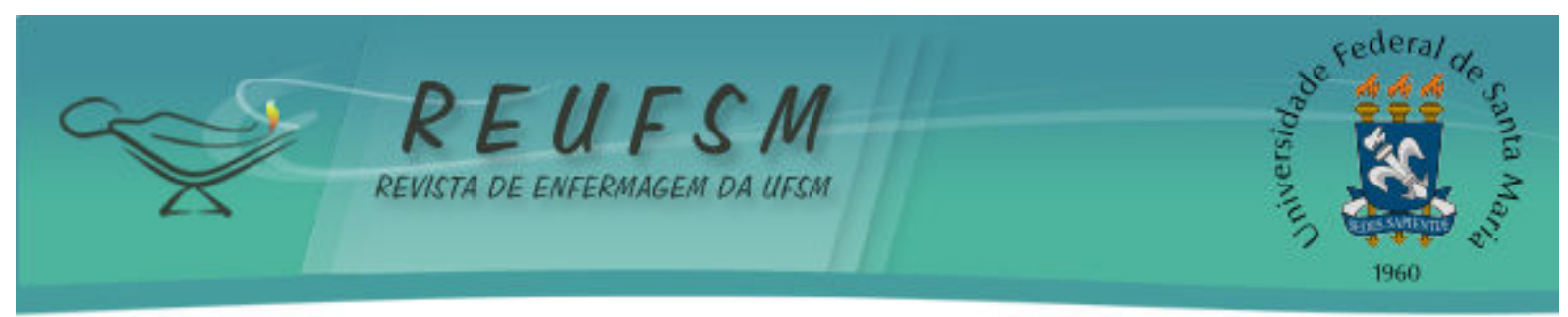

Você estar próximo, você realmente se vincular ao paciente, mas um vínculo inteligente que não haja interferência no âmbito emocional, mas fazer também com que o paciente tenha uma possibilidade, uma resposta do ponto de vista de responsabilidade diante do problema de saúde dele. (Di Cavalcante - Odontólogo)

O vínculo responsável e positivo significa estreitar relações com o outro de maneira saudável e construtiva, impedindo a relação de dependência e/ou o apego emocional. Formar vínculos exige a competência de se colocar no lugar do outro e fomentar a responsabilização sobre sua vida, auxiliando-o a transpor os obstáculos e problemas cotidianos e de saúde. ${ }^{17}$

0 vínculo pode ser analisado como um recurso terapêutico, inserido em um novo modo de fazer saúde por meio da superação do modelo biologicista para um olhar mais humanizado e responsável sobre o indivíduo, família e comunidade. ${ }^{22}$ Entretanto, para isso, faz-se necessário conquistar a confiança da comunidade na equipe de saúde. .,15-16 $^{\text {16 }}$ Inversamente, a equipe deve acreditar que, apoiados, os usuários sentir-se-ão protagonistas na superação das suas condições adversas. ${ }^{23}$

Observa-se que para os participantes da pesquisa a relevância do vínculo, enquanto recurso terapêutico, ultrapassa a dimensão do cuidado em si, promovendo a responsabilização sobre o usuário e sua situação de vida. Esse olhar dos preceptores do PET-Saúde da Família sobre o vínculo é importante por mostrar uma desconstrução das práticas assistenciais para uma prática profissional mais humana e próxima da realidade dos usuários influenciando, mesmo que indiretamente, a visão dos alunos.

\section{CONSIDERAÇÕES FINAIS}

Com base nos resultados do estudo, observou-se que a formação e o desenho do vínculo entre profissionais de saúde e usuários na ESF surge a partir das teias de relações existentes neste âmbito, baseadas no acolhimento, na responsabilização e na confiança entre esses indivíduos, perpassando também pelo reconhecimento do território de atuação.

O vínculo constituiu-se em um elemento imprescindível para o fortalecimento das relações na ESF. Corresponde ao mesmo tempo em um recurso terapêutico e em uma ferramenta relevante para o funcionamento da ESF, na medida em que intermedeia a comunicação entre os usuários e profissionais de saúde, concretizando o estabelecimento de uma relação muito próxima entre os mesmos.

Espera-se que os resultados apresentados neste artigo contribuam para o fortalecimento e crescimento da ESF ao mostrar a riqueza e importância das relações que a permeiam, valorizando-se a formulação do vínculo entre profissional de saúde e comunidade como uma ferramenta de cuidado.

Salienta-se a importância da descrição da visão dos preceptores do PET-Saúde da Família acerca dessa temática, mostrando-se uma transformação das práticas profissionais na Estratégia de Saúde da Família que serão repassadas para os discentes acompanhados pelos mesmos.

\section{REFERÊNCIAS}

1. Mendes EV. A atenção primária à saúde no SUS. Fortaleza: Escola de Saúde Pública do Ceará; 2002. 


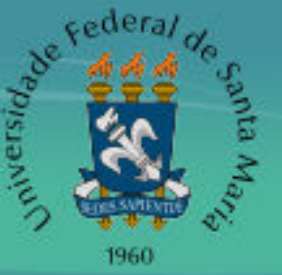

2. Brasil. Ministério da Saúde. Portaria $n^{\circ} 2.488$, de 21 de outubro de 2011. Aprova a Política Nacional de Atenção Básica, estabelecendo a revisão de diretrizes e normas para a organização da Atenção Básica, para a Estratégia Saúde da Família (ESF) e o Programa de Agentes Comunitários de Saúde (PACS). Brasília (DF): Ministério da Saúde; 2011.

3. Arantes LJ, Shimizu HE, Merchan-Hamann E. Contribuições e desafios da Estratégia Saúde da Família na Atenção Primária à Saúde no Brasil: revisão da literatura. Ciênc Saúde Coletiva. 2016;21(5):1499-510.

4. Moimaz SAS, Fadel CB, Yarid SD, Diniz DG. Saúde da Família: o desafio de uma atenção coletiva. Ciênc Saúde Coletiva. 2011;16 Supl 1:965-72.

5. Rodrigues Júnior B, Teixeira RB, Chevitarese L, Aroucha BN, Jorge RR, Caldas DM. A importância do vínculo entre profissional e paciente na Estratégia de saúde da Família: um relato de caso. Rev Rede de Cuidados em Saúde [Internet]. 2010 [acesso em 2014 nov 14];4(2):1-9.

Disponível

em:

http://publicacoes.unigranrio.edu.br/index.php/rcs/article/viewFile/1143/675.

6. Ilha S, Dias MV, Backes DS, Backes MTS. Vínculo profissional-usuário em uma equipe da Estratégia Saúde da Família. Ciênc Cuid Saúde. [Internet] 2014 jul/set;13(3):556-62. Disponível

http: //periodicos.uem.br/ojs/index.php/CiencCuidSaude/article/view/19661/pdf 229. DOI: 10.4025/cienccuidsaude.v13i3.19661.

7. Nogueira JA, Oliveira LCS, Sá LD, Silva CA, Silva DM, Villa TCS. Vínculo e acesso na estratégia saúde da família: percepção de usuários com tuberculose. Rev RENE. 2012;13(4):784-93.

8. Franco Júnior AJ, Conrado MOM, Andrade DE, Mioto DE. A importância do vínculo entre equipe e usuário para o profissional de saúde. Investigação [Internet]. 2008 [acesso em 2014 set 05];8(1-3):11-8. Disponível em: http://publicacoes.unifran.br/index.php/investigacao/article/view/60/26.

9. Brasil. Ministério da Saúde. Portaria Interministerial $n^{\circ} 1.802$, de 26 de agosto de 2008. Institui o Programa de Educação pelo Trabalho para a Saúde - PET-Saúde. Brasília (DF): Ministério da Saúde/Ministério da Educação; 2008.

10. Brasil. Ministério da Saúde. Portaria Interministerial $n^{\circ} 421$, de 3 de março de 2010. Institui o Programa de Educação pelo Trabalho para a Saúde (PET Saúde) e dá outras providências. Brasília (DF): Ministério da Saúde/Ministério da Educação; 2010.

11. Brasil. Ministério da Saúde. Conselho Nacional de Saúde. Resolução CNS nº 196, de 10 de outubro de 1996. Aprovar diretrizes e normas regulamentadoras de pesquisas envolvendo seres humanos. Brasília: Conselho Nacional de Saúde; 1996.

12. Bardin L. Análise de conteúdo. $1^{\mathrm{a}}$ ed. Lisboa: Edições 70; 2011.

13. Camargo BV. ALCESTE: um programa informático de análise quantitativa de dados textuais. In: Moreira ASP, Camargo VB, Jesuíno JC, Nóbrega SM, organizadores. Perspectivas teóricas e metodológicas em representações sociais. João Pessoa: UFPB/Ed. Universitária; 2005. p. 511-39.

14. Gomes ALC, Sá LD. As concepções de vínculo e a relação com o controle da tuberculose. Rev Esc Enferm USP. 2009;43(2):365-72. 


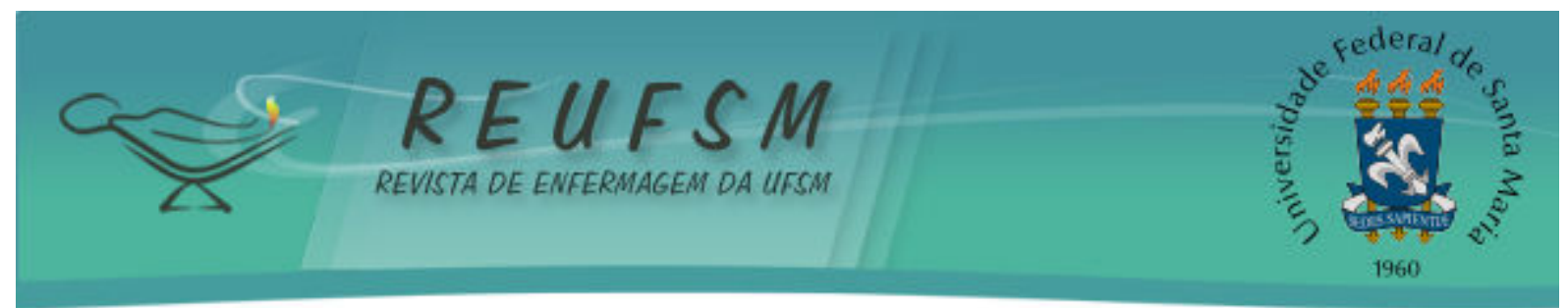

15. Schimith MD, Simon BS, Brêtas ACP, Budó, MLD. Relações entre profissionais de saúde e usuários durante as práticas em saúde. Trab Educ Saúde. 2011;9(3):479-503.

16. Franco ECD. A estratégia de saúde da família na perspectiva do usuário. Rev Enferm UFSM [Internet]. 2012 jan/abr [acesso em 2014 nov 25];2(1):49-58. Disponível em: http://cascavel.ufsm.br/revistas/ojs-2.2.2/index.php/reufsm/article/view/4002/3142.

17. Teixeira C, Silva CCS, Bernardes GC, Sá NPP, Prado RS. O vínculo entre usuários e equipes em duas unidades de saúde da família em um município do estado do Rio de Janeiro. Rev APS [Internet]. 2013 out/dez [acesso em 2016 jul 03];16(4):444-54. Disponível em: https://aps.ufjf.emnuvens.com.br/aps/article/view/1725/768.

18. Coelho MO, Jorge MSB. Tecnologia das relações como dispositivo do atendimento humanizado na atenção básica à saúde na perspectiva do acesso, do acolhimento e do vínculo. Ciênc Saúde Coletiva. 2009;14 Supl1:1523-31.

19. Mendes EV, organizador. Distritos sanitários: processo social de mudanças nas práticas sanitárias para Sistema Único de Saúde. São Paulo: Editora Hucitec/Rio de Janeiro: ABRASCO; 1993.

20. Silva MRF, Silveira LC, Pontes RJS, Vieira NA. O cuidado além da saúde: cartografia do vínculo, autonomia e território afetivo na saúde da família. REME Rev Min Enferm. 2015;19(1):249-54.

21. Medeiros CRG, Junqueira AGW, Schwingel G, Carreno I, Jungles LAP, Saldanha OMFL. A rotatividade de enfermeiros e médicos: um impasse na implementação da Estratégia de Saúde da Família. Ciênc Saúde Coletiva. 2010;15 Supl 1:521-31.

22. Sá LD, Gomes ALC, Nogueira JA, Villa TCS, Souza KMJ, Palha PF. Intersetorialidade e vínculo no controle da tuberculose na Saúde da Família. Rev Latinoam Enferm. 2011;19(2):387-95.

23. Campos GWS. Saúde Paidéia. $4^{\mathrm{a}}$ ed. São Paulo: Hucitec; 2007.

Data de recebimento: $14 / 03 / 2015$

Data de aceite: $26 / 07 / 2016$

Contato do autor responsável: Raionara Cristina de Araújo Santos

Endereço postal: Av. do Café, n. 2077, Apto. 126. Ribeirão Preto, SP, Brasil. CEP: $14050-230$

E-mail: raionara_cristina@yahoo.com.br 